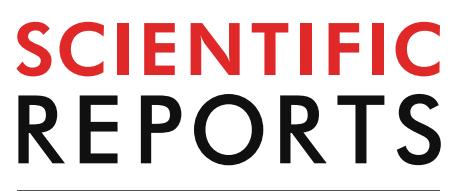

natureresearch

Check for updates

\title{
Insights into the molecular-level
} effects of atmospheric and room-temperature plasma on mononucleotides and single-stranded homoand hetero-oligonucleotides

\author{
Liyan Wang ${ }^{1,2,3,9}$, Hongxin $\mathrm{Zhao}^{4,9}$, Dong He${ }^{1}$, Yinan $\mathrm{Wu}^{1}$, Lihua $\mathrm{Jin}^{5}$, Guo Li ${ }^{6}$, Nan $\mathrm{Su}^{1}$, \\ Heping Li ${ }^{6}$ \& Xin-Hui Xing ${ }^{1,7,8 凶}$
}

Atmospheric and room-temperature plasma (ARTP) has been successfully developed as a useful mutation tool for mutation breeding of various microbes and plants as well animals by genetic alterations. However, understanding of the molecular mechanisms underlying the biological responses to ARTP irradiation is still limited. Therefore, to gain a molecular understanding of how irradiation with ARTP damages DNA, we irradiated the artificially synthesized mononucleotides of dATP, dTTP, dGTP, and dCTP, and the oligonucleotides of $\mathrm{dA}_{81}, \mathrm{dT}_{81}, \mathrm{dG}_{8}, \mathrm{dC}_{8}$, and $\mathrm{dA}_{2} \mathrm{dT}_{2} \mathrm{dG}_{2} \mathrm{dC}_{2}$ as chemical building blocks of DNA with ARTP for 1-4 min, identified the mononucleotide products using ${ }^{31} \mathrm{P}$ - and ${ }^{1} \mathrm{H}$-nuclear magnetic resonance spectroscopy (NMR), and identified the oligonucleotide products using matrix-assisted laser desorption/ionization time-of-flight mass spectrometry (MALDITOF MS) during ARTP treatment. The observed ${ }^{31} \mathrm{P}$-and ${ }^{1} \mathrm{H}$-NMR spectrum signals for the plasmatreated and untreated mononucleotides indicated that dATP was less stable to plasma irradiation than the other mononucleotides. The oligonucleotides after treatment with ARTP were found to have been broken into small fragments as shown by mass spectrometry, with the cleaved bonds and produced fragments identified according to their expected spectral $m / z$ values or molecular weights derived from their $\mathrm{m} / \mathrm{z}$ values. The stabilities of the oligonucleotides differed to ARTP irradiation, with $\mathrm{dT}_{8}$ being the most stable and was more beneficial to stabilizing single-stranded oligonucleotide structures compared to the other base groups ( $A, G$, and $C)$. This was consistent with the average potential energy level obtained by the molecular dynamic simulation of the oligonucleotides, i.e., $\mathrm{dT}_{8}>\mathrm{dC}_{8}>\mathrm{dA}_{8}>\mathrm{dG}_{8}>\mathrm{dA}_{2} \mathrm{dT}_{2} \mathrm{dG}_{2} \mathrm{dC}_{2}$. In summary, we found that ARTP treatment caused various structural changes to the oligonucleotides that may account for the wide and successful applications reported for ARTP-induced mutation breeding of various organisms.

${ }^{1}$ MOE Key Laboratory for Industrial Biocatalysis, Department of Chemical Engineering, Center for Synthetic and Systems Biology, Tsinghua University, Haidian District, Beijing 100084, People's Republic of China. ${ }^{2}$ Biobreeding Center, Wuxi Research Institute of Applied Technologies, Tsinghua University, Wuxi 214072, People's Republic of China. ${ }^{3}$ TmaxTree Biotechnology Co. Ltd., Luoyang 471023, People's Republic of China. ${ }^{4}$ Zhejiang Province Key Laboratory of Plant Secondary Metabolism and Regulation, College of Life Sciences and Medicine, Zhejiang Sci-Tech University, Hangzhou 310018, People's Republic of China. ${ }^{5}$ College of Bioengineering, Beijing Polytechnic, Beijing 100176, People's Republic of China. ${ }^{6}$ Department of Engineering Physics, Tsinghua University, Haidian District, Beijing 100084, People's Republic of China. ${ }^{7}$ Center for Synthetic and System Biology, Tsinghua University, Beijing, People's Republic of China. ${ }^{8}$ Institute of Biopharmaceutical and Health Engineering, Tsinghua Shenzhen International Graduate School, Shenzhen 518055, People's Republic of China. ${ }^{9}$ These authors contributed equally: Liyan Wang and Hongxin Zhao. ${ }^{\boxplus}$ email: liheping@tsinghua.edu.cn; xhxing@tsinghua.edu.cn 


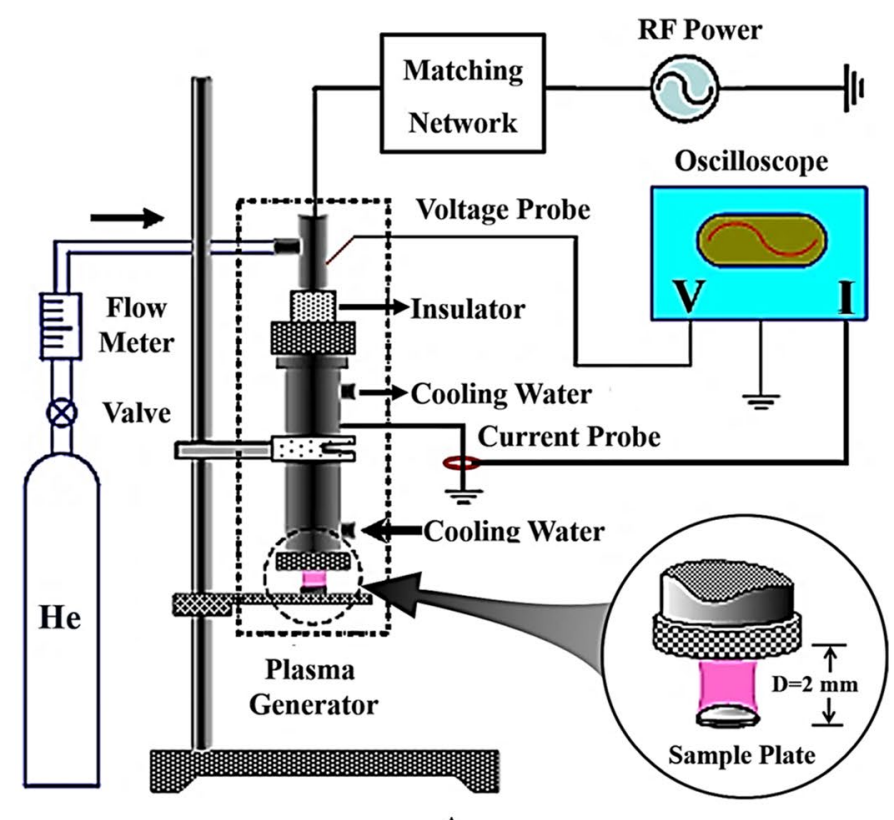

A

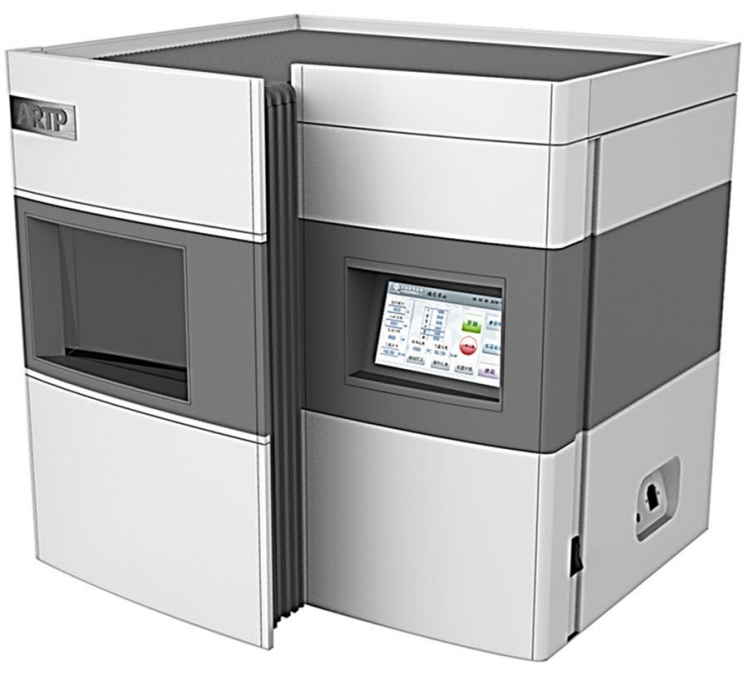

B

Figure 1. (A) Schematic of the ARTP-generating and -dosing instrumentation [(D) stand-off distance; RF, radio-frequency]; (B) Outlook of the instrument.

In the past decade, the effects of so called cold atmospheric plasma (CAP) such as atmospheric pressure glow discharge (APGD) plasma on biological phenomena have attracted great interest ${ }^{1-3}$. Extensive research has shown that APGD plasma causes DNA damage in a dose-dependent manner in both prokaryotic and eukaryotic cells $^{1-4}$. Hence, applications, including cancer and dental treatments, surface sterilization, surface modification of biocompatible materials, and surgery, have been developed ${ }^{5-18}$. APGD plasma can be generated at moderate temperatures $\left(\leq 50^{\circ} \mathrm{C}\right)^{6}$, and therefore it has been exploited to induce mutagenesis for mutational breeding ${ }^{1,4}$.

Previously, based on APGD, we developed an "atmospheric and room-temperature plasma (ARTP)" driven by a radio-frequency power supply and equipped with water-cooled bare-metallic copper electrodes (Fig. 1). We have employed this system to mutate the genomes of various microbes and plants as well as animals, including bacteria, microalgae, fungi, and yeast ${ }^{1,4,19-24}$. The results of those studies indicated that ARTP mutation is a rapid, effective, convenient, and multifaceted means of generating mutant libraries with sufficient diversity for the improvement of phenotypes. The mechanism(s) behind ARTP mutagenesis is (are) presumably related to the actions of reactive oxygen species (ROS)/reactive nitrogen species (RNS) generated by the reaction of plasma with the water environment of ARTP-treated cellular samples. These reactive species damage the cellular DNA and, consequently, induce the activation of repair systems such as the bacterial SOS repair system ${ }^{4,25}$. Since it was first developed, our ARTP mutation instrument has been successfully used to perform mutation breeding for more than 100 organisms $^{1}$. By quantitatively comparing the extent of DNA damage and mutation rates induced by different types of mutagens, including ARTP, 4-nitroquinoline-1-oxide plus N-methyl- $\mathrm{N}^{\prime}$-nitro- $\mathrm{N}$ nitrosoguanidine (MNNG), and ultraviolet radiation, ARTP was found to be a powerful mutagen with which to improve the organism characteristics ${ }^{26}$. However, the detailed molecular mechanism(s) by which ARTP damages DNA remains unclear.

To gain insights into the molecular mechanisms by which CAP damages DNA molecules, previous studies examined the reactivities of ROS and RNS toward nucleobases. Other studies focused on the effects of CAP or ARTP irradiation on isolated DNA molecules or analogs and then characterized them by gel electrophoresis, molecular combing, Fourier transform infrared spectroscopy, Raman spectroscopy, matrix-assisted laser desorption ionization-time of flight mass spectrometry (MALDI-TOF/MS), and/or high-performance liquid chromatography electrospray ionization-mass spectrometry (HPLC-ESI-MS/MS) ${ }^{4,27,28}$. In the aforementioned studies, structural comparison of plasma-treated and untreated DNA molecules or analogs demonstrated that irradiation with plasma can result in DNA fragmentation. The effects of helium-based ARTP on plasmid DNA have also been investigated in our previous work ${ }^{26-28}$. However, details of the structural changes and base-breakage patterns during the DNA-damage process(s) by plasma are still unknown.

For the work reported herein, to investigate the damage pattern of DNA by ARTP treatment at molecular level, we developed a method employing plasma-based breakage of DNA bases in mono-, oligo-, and polynucleotides using the artificially synthesized mononucleotides of dATP, dTTP, dGTP, and dCTP, and the five oligonucleotides of $\mathrm{dA}_{8}, \mathrm{dT}_{8}, \mathrm{dG}_{8}, \mathrm{dC}_{8}$, and $\mathrm{dA}_{2} \mathrm{dT}_{2} \mathrm{dG}_{2} \mathrm{dC}_{2}$, and treated them by a previously developed, helium-based ARTP system ${ }^{4}$. After treatment of the oligonucleotides with ARTP for different time periods, the products were characterized by ${ }^{31} \mathrm{P}$ - and ${ }^{1} \mathrm{H}-\mathrm{NMR}$ spectroscopy, and MALDI-TOF/MS to identify chemical changes induced by irradiation with ARTP. The molecular dynamic simulation was also performed using Discovery Studio v2.5 (DS) to estimate the stability of the synthesized oligonucleotides. 

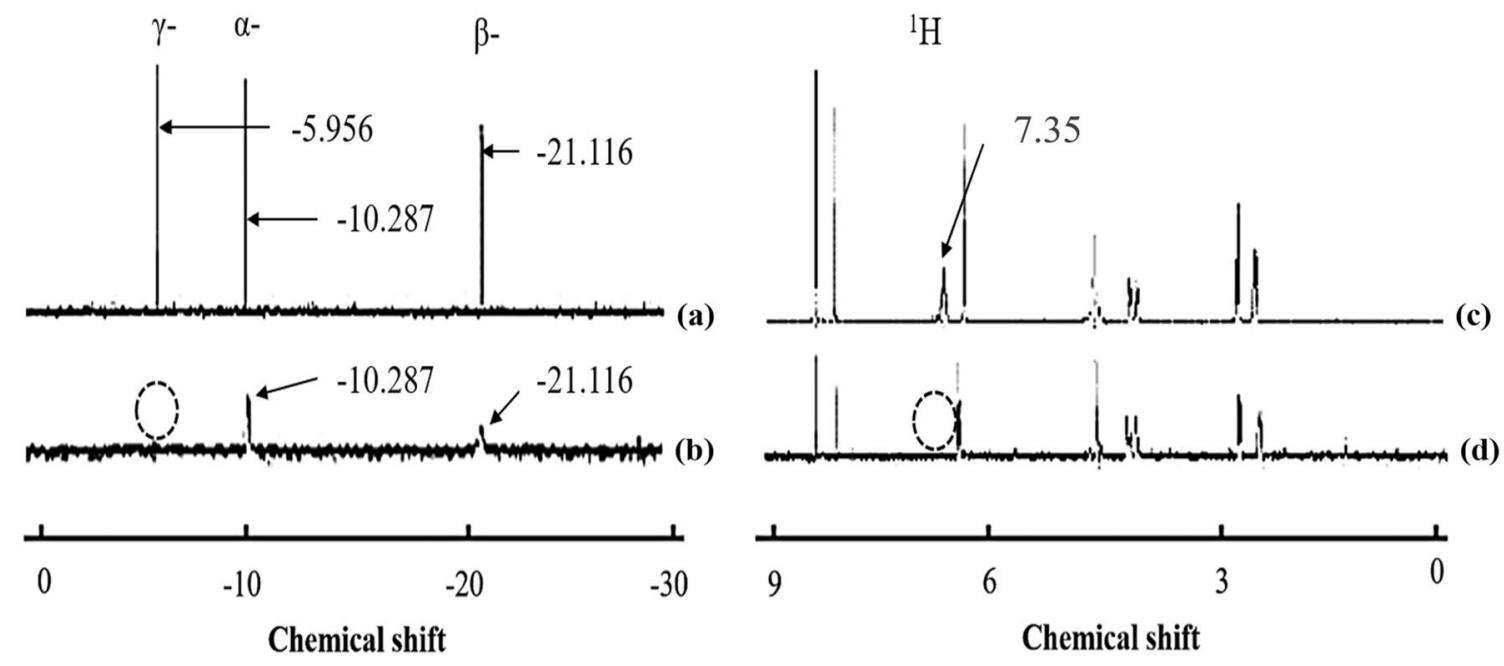

Figure 2. ${ }^{31} \mathrm{P}$ - and ${ }^{1} \mathrm{H}-\mathrm{NMR}$ spectra of dATP before and after ARTP-treatment $2 \mathrm{~min}\left(\mathrm{D}_{2} \mathrm{O}\right.$ as solvent to dissolve samples). (a,b) ${ }^{31} \mathrm{P}-\mathrm{NMR}$ spectra of dATP before (a) and after (b) ARTP treatment. (c,d) ${ }^{1} \mathrm{H}-\mathrm{NMR}$ spectra of dATP before (c) and after (d) ARTP treatment. The signals at $\delta=-6.0,-10.3$ and -21.1 are those of the $\gamma^{-}, \alpha$ - and $\beta$-phosphates.

Results. ARTP-induced effects on the molecular structures of mononucleotides. A mononucleotide (dNTP) consists of three major parts: a nitrogen base, a sugar moiety, and a triphosphate. Only the nitrogen bases differ between the four mononucleotides. NMR is a powerful analytical tool to determine the structures of organic compounds by analyzing the environments of ${ }^{1} \mathrm{H},{ }^{13} \mathrm{C}$, and ${ }^{31} \mathrm{P}$ nuclei. Thus, acquisition of ${ }^{31} \mathrm{P}$-and ${ }^{1} \mathrm{H}$-NMR spectra of the plasma-treated mononucleotides was helpful in determining the chemical and structural changes.

The ${ }^{31} \mathrm{P}-\mathrm{NMR}$ spectra of dATP before and after ARTP treatment are shown in Fig. 2a,b. The chemical shifts $(\delta)$ at $-6.0,-10.3$, and -21.1 in the ${ }^{31} \mathrm{P}$-NMR spectrum are those of the $\gamma-, \alpha$ - and $\beta$-phosphates, respectively. The $\gamma$-phosphate group of dATP disappeared after 4-min treatment with ARTP, and the $\alpha$ - and $\beta$-phosphate groups also were cleaved when treated for an additional time (Fig. 2a,b). Structural changes related to the deoxyribose moieties and bases were also seen in the ${ }^{1} \mathrm{H}$-NMR spectra (Fig. $2 \mathrm{c}, \mathrm{d}$ ). The signal at $\delta=7.35$ in the spectrum of dATP [Fig. 2c; Fig. S1(2)], which is that for the hydrogens of the amino group at C6 of adenine, disappeared quickly and completely upon treatment with plasma (Fig. 2d). Actually as a chemical change, the $\delta=7.35$ signal in the spectrum as time went by also disappeared slowly because the $\mathrm{NH}_{2}$ group was going to exchange with $\mathrm{ND}_{2}$ in deuterium oxide. The signal at $\delta=-0.51$ in the ${ }^{1} \mathrm{H}$-NMR spectrum of dCTP was a new peak after treated by ARTP [Fig. S1(4)]. It also indicated that the structure of dCTP has changed. Interestingly, the plasma-induced structural changes in dGTPs and dTTPs by ARTP treatment were not as obvious as dATP and dCTP from the ${ }^{1} \mathrm{H}-\mathrm{NMR}$ spectrum [Fig. S1(6),(8)], and the reason would be discussed latter.

The above results suggested that the phosphate groups as one of chemical groups of the dATP and dCTP mononucleotides were relatively susceptible to cleavage upon ARTP treatment than other chemical groups. Notably, deoxyribose and the individual, isolated bases were stable to ARTP treatment. However, the stability of the deoxyribose moiety after treatment with ARTP decreased when covalently bonded to a triphosphate via a phosphodiester bond (Fig. S1). These NMR spectra indicated that the chemical natures of the mononucleotides determined their stability to irradiation with ARTP (Fig. S1).

Structural changes of the oligonucleotides induced by ARTP treatment. The changes in the oligonucleotides induced by ARTP treatment were characterized by MALDI-TOF/MS. To correct for background noise, the mass spectrum of the solvent, distilled water, was acquired in parallel (Fig. S2). Mass peaks were found for the distilled water sample when the $\mathrm{m} / z$ ratio was $<650$ (Fig. S2), whereas almost no signals were observed when the $\mathrm{m} / z$ ratio was $>680$ (Fig. S2). Therefore, the mass spectra of $\mathrm{dA}_{8}, \mathrm{dG}_{8}, \mathrm{dC}_{8}$, and $\mathrm{dT}_{8}$ were acquired between $\mathrm{m} / \mathrm{z}$ values of 680 and 2,800 (Fig. 3a-p). Except for two noise signals with $\mathrm{m} / \mathrm{z}$ values of 1,256.4 and $1,105.2$ in the spectrum of $\mathrm{dG}_{8}$ (Fig. 3e), no other noise signals were observed that might reflect the presence of contaminants. The lack of extraneous signals indicated that the oligonucleotides were of high quality and suitable for structural analysis by MALDI-TOF/MS (Fig. 3a,e,i,m).

After $\mathrm{dA}_{8}$ and $\mathrm{dG}_{8}$ had been treated with ARTP for 1, 2, or 4 min, several different signals were detected in their mass spectra (Fig. $3 \mathrm{~b}-\mathrm{d}, \mathrm{f}-\mathrm{h}$ ) respectively. The oligonucleotides were degraded into smaller fragments upon treatment with plasma. Four new peaks appeared at different $\mathrm{m} / \mathrm{z}$ positions (Fig. $3 \mathrm{~b}-\mathrm{d}$ ). Four new signals at small $\mathrm{m} / z$ increased in intensity with increase of ARTP treatment time in the spectrum of $\mathrm{dA}_{8}$, whereas the signal of intact $\mathrm{dA}_{8}(m / z=2,441.2)$ had disappeared from 2 min ARTP treatment (Fig. $3 c$,d). Similar results, which several new peaks appeared at different $\mathrm{m} / \mathrm{z}$ position were obtained from the spectra of $\mathrm{dG}_{8}$ (Fig. $\left.3 \mathrm{f}-\mathrm{h}\right)$. And signals' intensity in the spectrum increased with time treated by ARTP (Fig. $3 \mathrm{f}-\mathrm{h}$ ). Moreover, all signal intensities corresponding to products formed upon treatment of $\mathrm{dA}_{8}$ and $\mathrm{dG}_{8}$ with ARTP increased with time. This result suggested that more new fragments were formed along with the prolonged treatment time for poly 

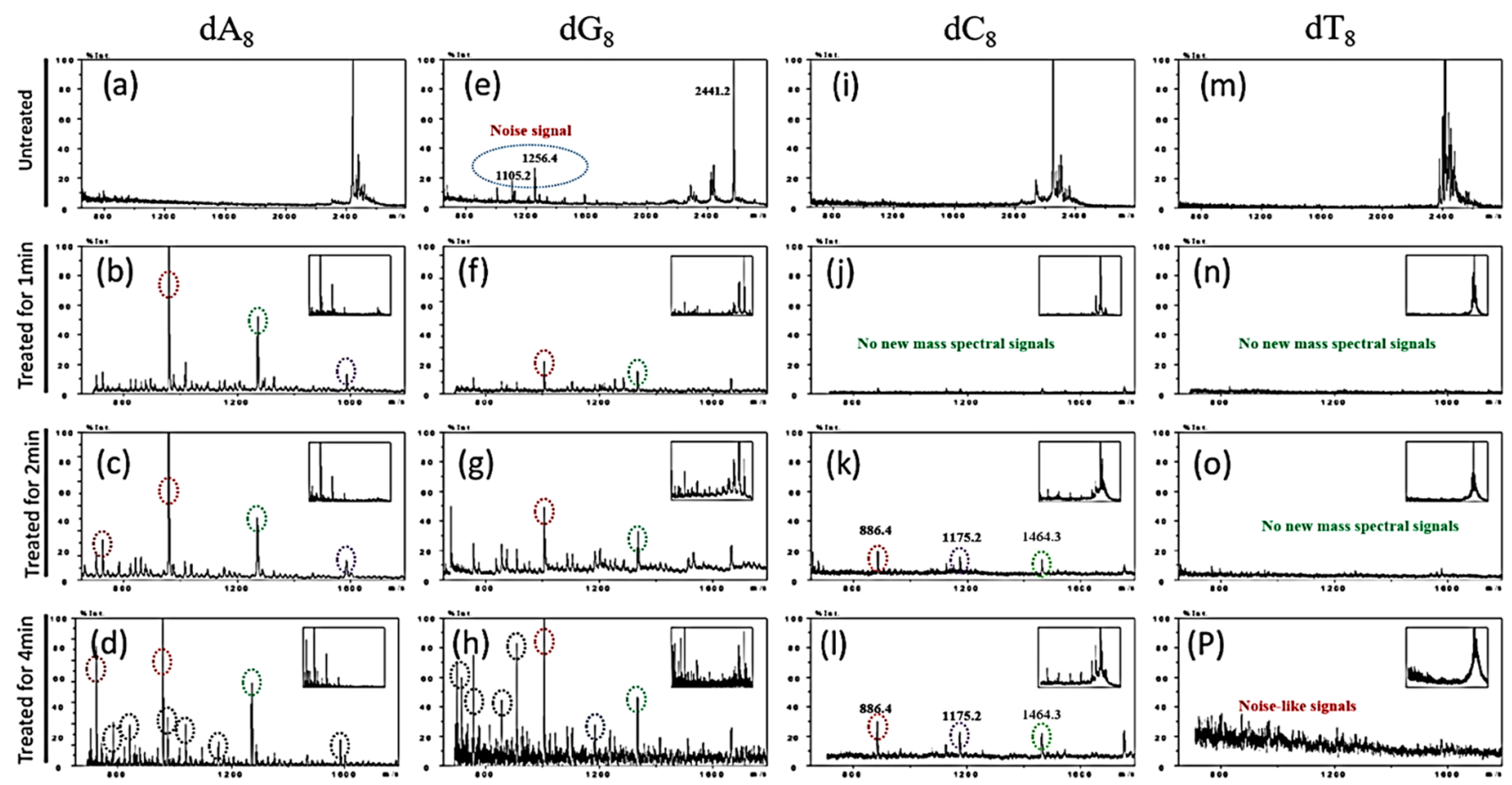

Figure 3. MALDI-TOF/MS of the oligonucleotides. The mass spectra were acquired over an $m / z$ range of 6802,800 . To clearly display the spectral regions containing the nucleotide fragments present after ARTP treatment, the spectral region between $\mathrm{m} / z 680$ and $\mathrm{m} / z 1,600$ is shown in the larger diagrams with the complete spectra shown in the inserts. The image of mass spectrogram of $680 \sim 2,800(\mathrm{~m} / \mathrm{z})$ is shown in the upper right corner.

A and G (Fig. 3b-d,f-h). These results clearly showed that poly A and G were broken rapidly with increase of ARTP treatment time, but the quantitative analysis for the oligonucleotide breakage pattern upon ARTP treatment needs to be performed further.

Interestingly, no new mass spectral signals were detected for $\mathrm{dC}_{8}$ after an ARTP treatment of $1 \mathrm{~min}$. When $\mathrm{dC}_{8}$ was treated for $2 \mathrm{~min}$ and $4 \mathrm{~min}$, three new signals with weak intensities were detected at $\mathrm{m} / z=886.4,1,175.2$, and $1,464.3$ (Fig. 3k,1). These observations suggested that $\mathrm{dC}_{8}$ was more resistant to ARTP-induced fragmentation than $\mathrm{dA}_{8}$ and $\mathrm{dG}_{8}$ under the same conditions. Concerning $\mathrm{dT}_{8}$, no MALDI-TOF/MS signals associated with new fragments were observed after $\mathrm{dT}_{8}$ had been treated with ARTP for 1-2 min (Fig. 3n,o). When treatment was increased to $4 \mathrm{~min}$, however, the signal intensity of intact $\mathrm{dT}_{8}$ decreased somewhat, and several very weak, noise-like signals were observed. Therefore, $\mathrm{dT}_{8}$ was more stable to ARTP treatment, as hardly any fragments smaller than the original ion were consistently seen (Fig. 3p).

In summary, the several bonds within the oligonucleotide structures were broken by ARTP treatment, with the adenine $(A)$ and guanine $(\mathrm{G})$ purine bases being less stable to ARTP than the cytosine $(\mathrm{C})$ and thymine $(\mathrm{T})$ pyrimidine bases. In addition, $\mathrm{dT}_{8}$ was the most stable to ARTP treatment.

Identification of the oligonucleotide fragments generated by ARTP treatment. The relationship between the molecular weight/mass of a molecule and the $\mathrm{m} / \mathrm{z}$ values of oligonucleotides can be determined simply by reading the $m / z$ values from the MALDI-TOF/MS spectra and solving the below equation. The chemical structure formulas of the fragments and the positions of the broken bonds can then be deduced, expressed as the following equation:

$$
m / z=\left(\mathrm{MW}+\mathrm{nH}^{+}\right) / \mathrm{n}
$$

where $\mathrm{m} / \mathrm{z}$ is the mass-to-charge ratio marked on the abscissa of the spectrum, $M W$ is the molecular mass of the molecule, $n$ is the integer number of charges on the ions, and $H$ is the mass of a proton $=1.008 \mathrm{Da}^{29}$. The molecular weights of major peaks in the spectra (Figs. 4, 5,6 and 7) was calculated using the above equation and the values of molecular mass difference between two peaks were named $\Delta_{\mathrm{A}}, \Delta_{\mathrm{A} 1}, \Delta_{\mathrm{A} 2}$ and $\Delta_{\mathrm{A} 3}$ (Table 1).

Notably, as mentioned above, $\mathrm{dA}_{8}$ was almost completely fragmented by a 4-min treatment with plasma. Accordingly, the chemical structures of the fragments and the bonds broken upon treatment with plasma were deduced based on the change in molecular weight $(\Delta M W)$ values between different fragments (Fig. $4 \mathrm{a})$. The molecular weights and chemical formulas of the fragments corresponding to the main peaks in each spectrum were deduced and are listed in Table 1. Certain bonds in the $\mathrm{dA}_{8}$ skeleton, involving deoxyribose and/or a phosphate, were broken. Moreover, two fragments of $\mathrm{dA}_{8}$ with molecular weights of $\Delta_{\mathrm{A} 1}(134)$ and $\Delta_{\mathrm{A} 2}$ (118) (Fig. 4a) appear to correspond to those of adenine $\mathrm{C}_{5} \mathrm{H}_{4} \mathrm{~N}_{5}-\mathrm{H}$ and adenine $\mathrm{C}_{5} \mathrm{H}_{3} \mathrm{~N}_{4}-\mathrm{NH}_{3}$ (i.e., minus an amino group) (Table 1), respectively. These results suggested that the most easily broken bonds in $\mathrm{dA}_{8}$ were the $\mathrm{C}-\mathrm{N}$ bond 


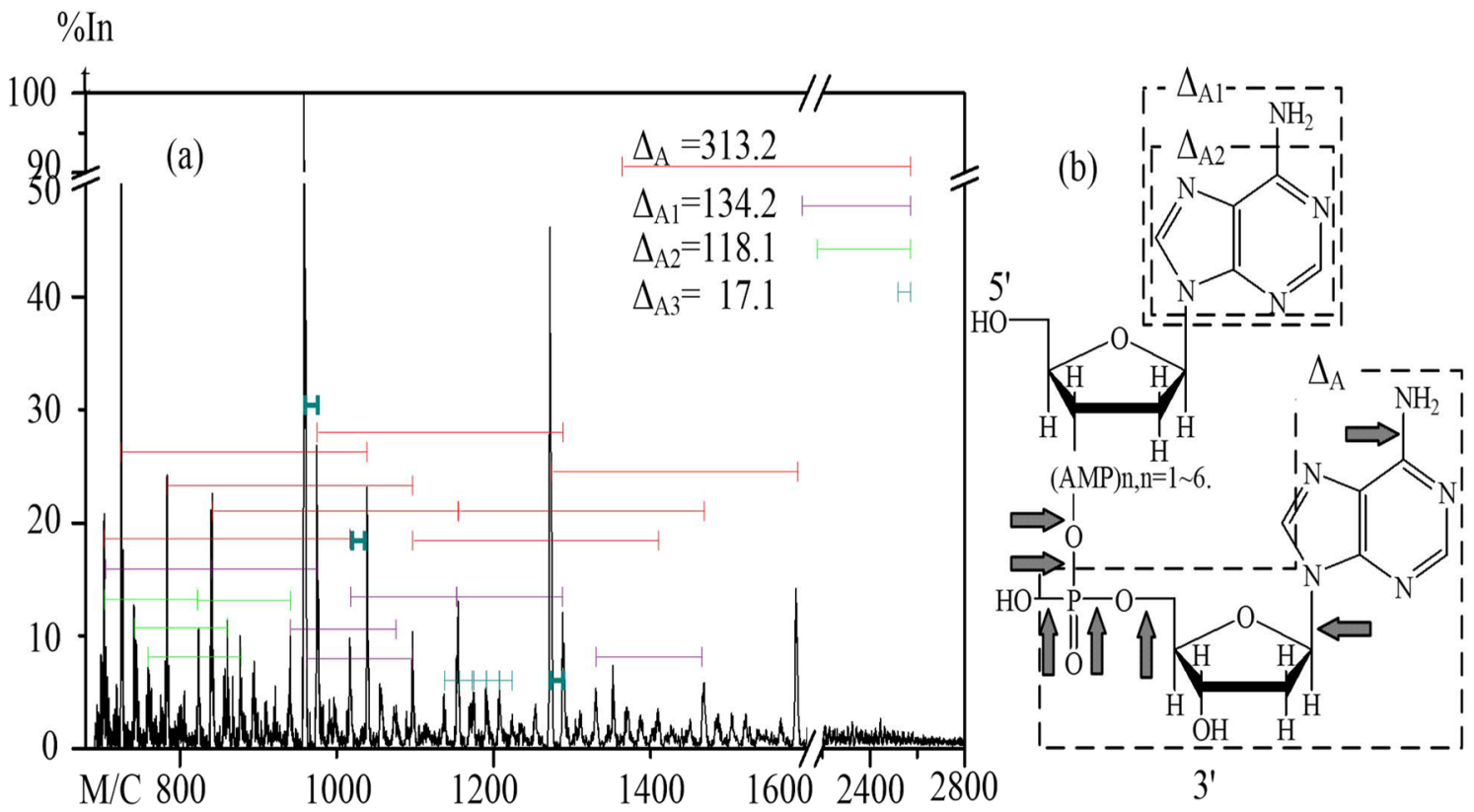

Figure 4. The MALDI-TOF mass spectrum of $\mathrm{dA}_{8}$ after a 4-min ARTP treatment. (a) The MALDI-TOF mass spectrum of $\mathrm{dA}_{8}$ showing differences in $\mathrm{m} / z$ values between various signals. (b) The structure of $\mathrm{dA}_{8}$. The arrows indicate bonds that would have been cleaved to generate fragments having the molecular weights assigned in the mass spectrum.
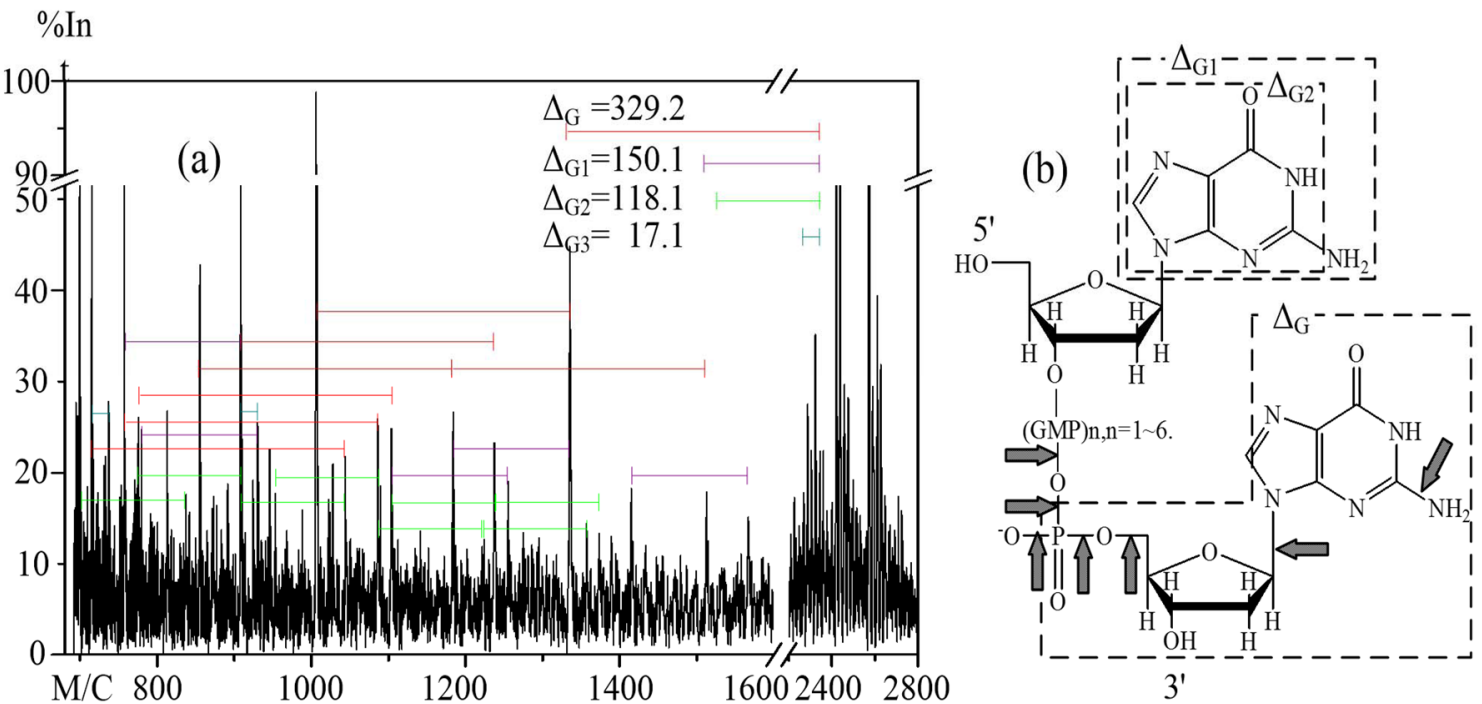

Figure 5. The MALDI-TOF mass spectrum of $\mathrm{dG}_{8}$ after a 4-min ARTP treatment. (a) MALDI-TOF mass spectrum of $\mathrm{dG}_{8}$ showing differences in $\mathrm{m} / z$ values between various signals. (b) The structure of $\mathrm{dG}_{8}$. The arrows indicate bonds that would have been cleaved to generate fragments having the molecular weights assigned in the mass spectrum.

between $\mathrm{C}-1^{\prime}$ of the deoxyribose and $\mathrm{N}-9$ of adenine, the $\mathrm{N}-\mathrm{C}$ bond between the amino $\mathrm{N}$ and $\mathrm{C}$ of adenine, and the P-O bond between the phosphate and hydroxyl group (Fig. $4 \mathrm{~b}$ ).

The spectrum of $\mathrm{dG}_{8}$ was similar to that of $\mathrm{dA}_{8}$ after ARTP treatment, except for a residual amount of $\mathrm{dG}_{8}$ after a 4-min exposure to plasma (Figs. $3 \mathrm{~h}$ and $5 \mathrm{a}$ ). The differences between the molecular weights of the main signals were denoted $\Delta_{\mathrm{G}}, \Delta_{\mathrm{G} 1}$, and $\Delta_{\mathrm{G} 2}$ and corresponded to GMP minus the two oxonium ions, an intact guanine, and a guanine without the amino group, respectively (Table 1 ). As was the case with $\mathrm{dA}_{8}$ (Fig. $4 \mathrm{~b}$ ), the $\mathrm{C}-\mathrm{N}$ bond between $\mathrm{C}-1^{\prime}$ and $\mathrm{N}-9$, the $\mathrm{N}-\mathrm{C}$ bond between the amino $\mathrm{N}$ and $\mathrm{C}$, and the $\mathrm{P}-\mathrm{O}$ bond between the phosphorous and hydroxyl group were the most easily cleaved. Both adenine and guanine are planar purine bases, and the structures of these bases might inhibit interaction with their deoxyribose and phosphate components and show the more stability to the connection ${ }^{30-32}$ (Fig. 5b). 


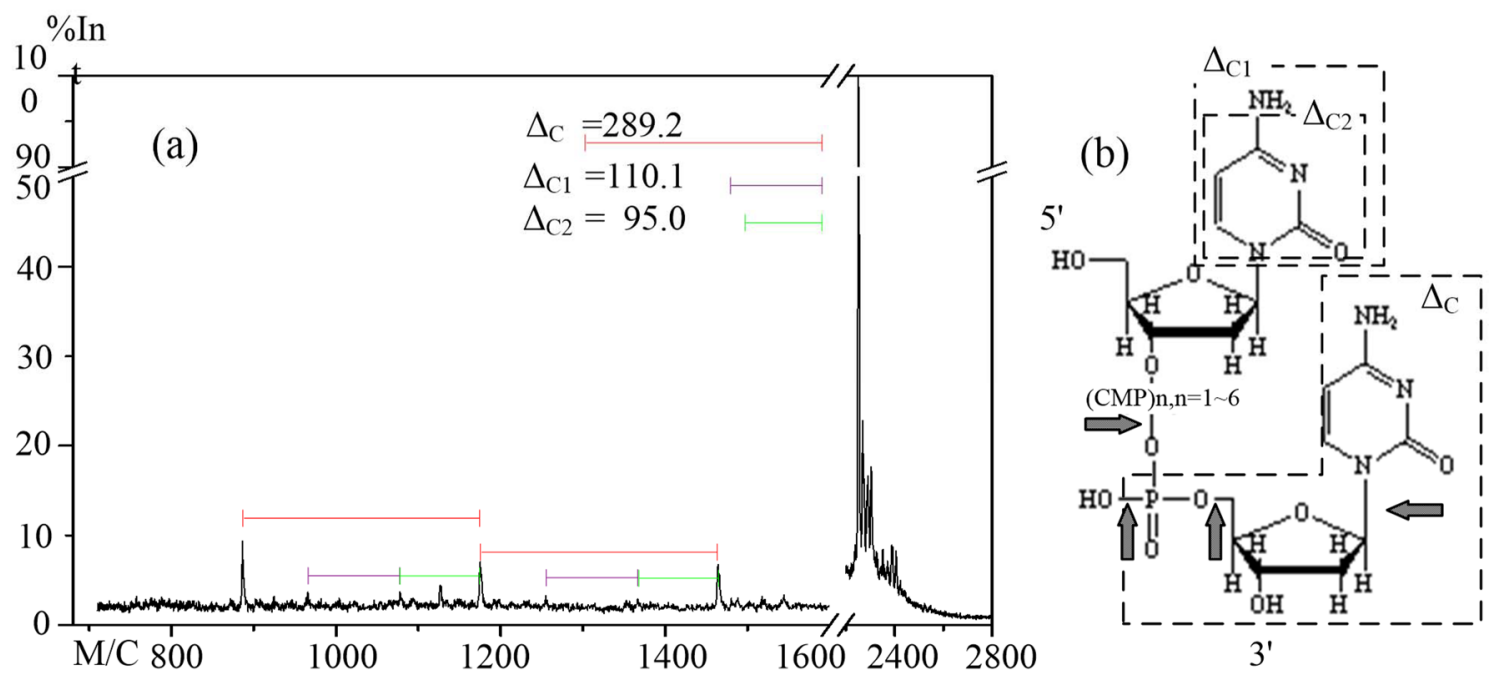

Figure 6. The MALDI-TOF mass spectrum of $\mathrm{dC}_{8}$ after a 4-min ARTP treatment. (a) MALDI-TOF mass spectrum of $\mathrm{dC}_{8}$ showing differences in $\mathrm{m} / z$ values between various signals. (b) The structure of $\mathrm{dC}_{8}$. The arrows indicate bonds that would have been cleaved to generate fragments having the molecular weights assigned in the mass spectrum.

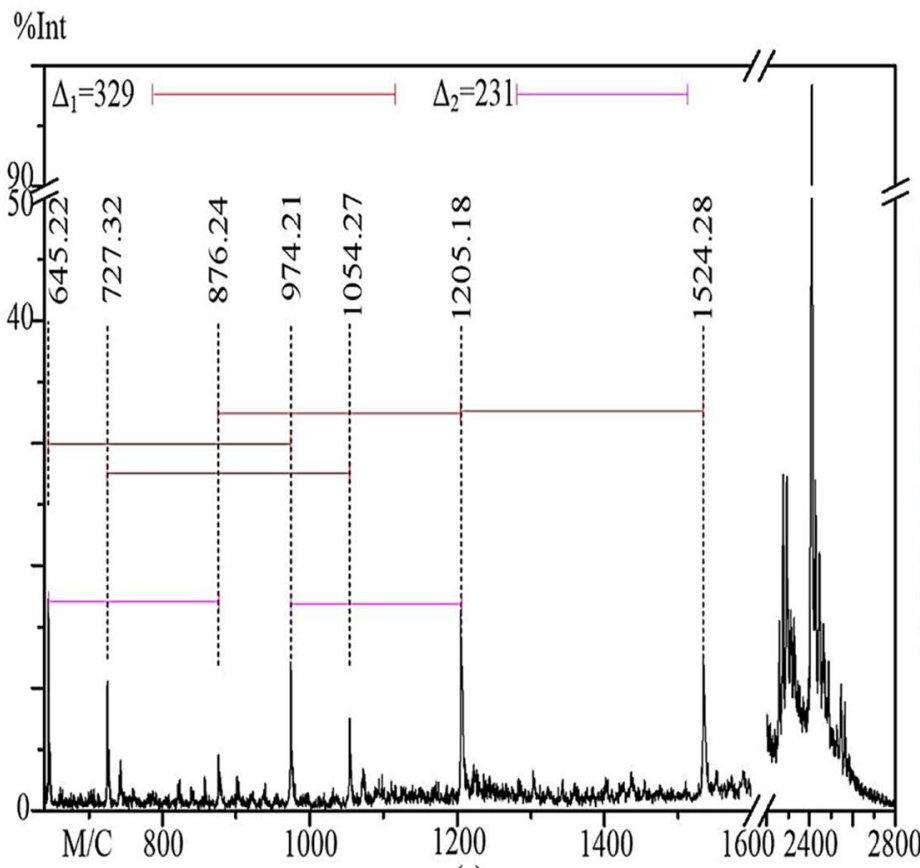

(a)

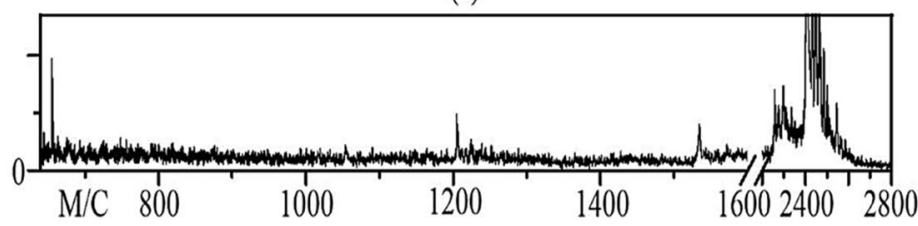

(b)

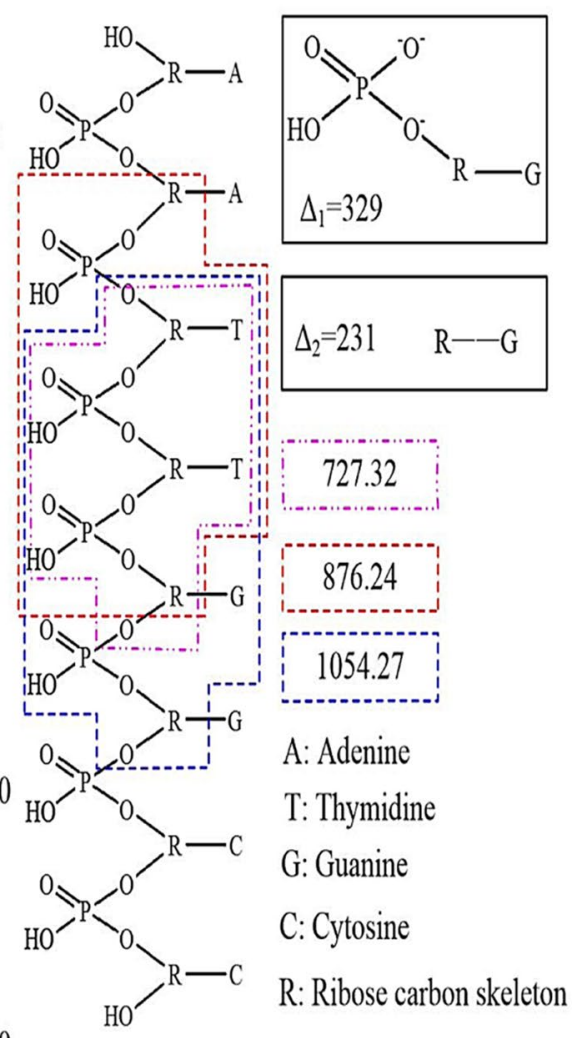

(c)

Figure 7. The MALDI-TOF mass spectrum of $\mathrm{dA}_{2} \mathrm{dT}_{2} \mathrm{dG}_{2} \mathrm{dC}_{2}$ after a 2-min ARTP treatment. (a) Mass spectrum of $\mathrm{dA}_{2} \mathrm{dT}_{2} \mathrm{dG}_{2} \mathrm{dC}_{2}$ after a 2-min plasma treatment. (b) Mass spectrum of untreated $\mathrm{dA}_{2} \mathrm{dT}_{2} \mathrm{dG}_{2} \mathrm{dC}_{2}$. (c) Assigned fragments produced by plasma treatment for the signals observed in the spectrum shown in (a). 


\begin{tabular}{|c|c|c|c|c|}
\hline Oligonucleotide & Fragment & Molecular formula & Molecular mass (Da) & $\begin{array}{l}\text { Chemical } \\
\text { group }\end{array}$ \\
\hline \multirow{4}{*}{$\mathrm{dA}_{8}$} & $\Delta_{\mathrm{A}}$ & $\mathrm{C}_{10} \mathrm{H}_{12} \mathrm{~N}_{5} \mathrm{O}_{5} \mathrm{P}-(\mathrm{OH})_{2}$ & 313.2 & AMP \\
\hline & $\Delta_{\mathrm{A} 1}$ & $\mathrm{C}_{5} \mathrm{H}_{4} \mathrm{~N}_{5}-\mathrm{H}$ & 134.2 & Adenine \\
\hline & $\Delta_{\mathrm{A} 2}$ & $\mathrm{C}_{5} \mathrm{H}_{3} \mathrm{~N}_{4}-\mathrm{NH}_{3}$ & 118.2 & $\begin{array}{l}\text { Adenine minus } \\
\text { its amino group }\end{array}$ \\
\hline & $\Delta_{\mathrm{A} 3}$ & $\mathrm{NH}_{3}$ & 17.1 & Amino group \\
\hline \multirow{4}{*}{$\mathrm{dG}_{8}$} & $\Delta_{\mathrm{G}}$ & $\mathrm{C}_{10} \mathrm{H}_{12} \mathrm{~N}_{5} \mathrm{O}_{8} \mathrm{P}-\left(\mathrm{O}^{-}\right)_{2}$ & 329.2 & GMP \\
\hline & $\Delta_{\mathrm{G} 1}$ & $\mathrm{C}_{5} \mathrm{H}_{4} \mathrm{~N}_{5} \mathrm{O}-\mathrm{H}$ & 150.1 & Guanine \\
\hline & $\Delta_{\mathrm{G} 2}$ & $\mathrm{C}_{5} \mathrm{H}_{2} \mathrm{~N}_{4} \mathrm{O}-\mathrm{NH}_{3}$ & 118.1 & $\begin{array}{l}\text { Guanine minus } \\
\text { its amino group }\end{array}$ \\
\hline & $\Delta_{\mathrm{G} 3}$ & $\mathrm{NH}_{3}$ & 17.1 & Amino group \\
\hline \multirow{3}{*}{$\mathrm{dC}_{8}$} & $\Delta_{\mathrm{C}}$ & $\mathrm{C}_{9} \mathrm{H}_{12} \mathrm{~N}_{3} \mathrm{O}_{6} \mathrm{P}-(\mathrm{OH})_{2}$ & 289.2 & CMP \\
\hline & $\Delta_{\mathrm{C} 1}$ & $\mathrm{C}_{4} \mathrm{H}_{4} \mathrm{~N}_{3} \mathrm{O}-\mathrm{H}$ & 110.1 & Cytosine \\
\hline & $\Delta y$ & $\mathrm{C}_{4} \mathrm{H}_{2} \mathrm{~N}_{2} \mathrm{O}-\mathrm{NH}_{3}$ & 95.0 & $\begin{array}{l}\text { Cytosine minus } \\
\text { its amino group }\end{array}$ \\
\hline $\mathrm{dT}_{8}$ & \multicolumn{4}{|c|}{ Stable to ARTP treatment } \\
\hline \multirow[b]{2}{*}{$\mathrm{dA}_{2} \mathrm{dT}_{2} \mathrm{dG}_{2} \mathrm{dC}_{2}$} & $\Delta_{1}$ & $\mathrm{HO}_{4} \mathrm{P}^{2-}-\mathrm{R}$-Guanine & 329 & GMP \\
\hline & $\Delta_{2}$ & R-Guanine & 231 & $\begin{array}{l}\text { Carbon skeleton } \\
\text { of deoxyribose } \\
\text { plus a guanine }\end{array}$ \\
\hline
\end{tabular}

Table 1. Fragments of oligonucleotides produced by treatment with plasma and identified by MALDI-TOF/ MS (R, carbon skeleton of deoxyribose).

As shown in Fig. 6, the molecular structure of $\mathrm{dC}_{8}$, according to its mass spectrum, was more stable to ARTP treatment than was $\mathrm{dA}_{8}$ or $\mathrm{dG}_{8}$. After $\mathrm{dC}_{8}$ was treated with ARTP for 4 min, three weak peaks were detected at $\mathrm{m} / z$ values of $886.4,1,175.2$, and $1,464.3$ (Figs. $3 \mathrm{i}$ and $6 \mathrm{a}$ ). The $\Delta m / z$ value $\left(\Delta_{C}\right.$ ) that corresponds to the difference between adjacent peaks was 289.2, which is that of dCMP (Fig. 6a). In addition, two other weak signals were detected at $m / z$ values of 972.2 and $1,082.3$ (Fig. 6a). The $\Delta m / z$ values were $110.1\left(\Delta_{\mathrm{C} 1}\right)$ and $95.0\left(\Delta_{\mathrm{C} 2}\right)$, which agree with the theoretical $\mathrm{m} / z$ values for cytosine and phosphate, respectively (Fig. $6 \mathrm{~b}$ and Table 1). The phosphodiester fragments between the phosphorous and the hydroxyl group in the deoxyribose of $\mathrm{dC}_{8}$ appeared to be readily cleaved by ARTP treatment (Fig. 6b).

Finally, when the ARTP treatment time was $4 \mathrm{~min}$, a weak signal was detected that could not be assigned to a fragment of $\mathrm{dT}_{8}$ (Fig. 3p). The appearance of this peak suggested that a small number of $\mathrm{dT}_{8} \mathrm{molecules}$ were cleaved into small fragments by ARTP treatment (Fig. 3p).

The aforementioned observations, i.e., that the stability of each of $\mathrm{dC}_{8}$ and $\mathrm{dT}_{8}$, which contain pyrimidine bases, was higher than the stability of $\mathrm{dA}_{8}$ or $\mathrm{dG}_{8}$, which contain purine bases, suggested that the relatively larger purine bases have ribose-phosphate backbones that are relatively more exposed to the environment as a consequence of linearization of the chains compared with the pyrimidine bases of $\mathrm{dC}_{8}$ and $\mathrm{dT}_{8}$; hence, this aspect made the backbones of $\mathrm{dA}_{8}$ and $\mathrm{dG}_{8}$ more susceptible to ARTP-induced cleavage.

To begin to characterize the ARTP-induced fragmentation products of single-stranded hetero- oligonucleotide chains, the synthetic oligonucleotide, $\mathrm{dA}_{2} \mathrm{dT}_{2} \mathrm{dG}_{2} \mathrm{dC}_{2}$, was subjected to the treatment with ARTP for 2 min as described for the homo-oligonucleotide chains, and the resulting fragments were also identified by MALDI-TOF/ MS (Fig. 7). Differences between pairs of signals shown in Fig. 7a were $329\left(\Delta_{1}\right)$ and $231\left(\Delta_{2}\right)$, which agree with the molecular weight of GMP and that of a guanine attached to the carbon skeleton of deoxyribose (Fig. 5a), respectively. The speculative chemical structures of assigned fragments (Fig. 7c) produced by plasma treatment for the peak signals with $\mathrm{m} / z$ values of $727.22,876.24$, and $1,054.27$ observed in the spectrum in Fig. 7a, respectively. The spectrum of nontreated $\mathrm{dA}_{2} \mathrm{dT}_{2} \mathrm{dG}_{2} \mathrm{dC}_{2}$ by ARTP is shown in Fig. $7 \mathrm{~b}$ and also contains signals with $\mathrm{m} / \mathrm{z}$ values of $727.32,876.24$, and $1,054.27$ corresponding to Fig. $7 \mathrm{a}$, respectively.

The aforementioned results indicated that the phosphodiester fragments of the mononucleotides and oligonucleotides were easily broken by ARTP. In addition, the N-C bonds between the bases and the deoxyribose moieties of $\mathrm{dA}_{8}$ and $\mathrm{dG}_{8}$ were also easily broken to generate adenine and guanine, respectively. Compared with the cleavage of adenine and guanine from their homonucleotide chains, cleavage of thymine and cytosine was more difficult. The interpretation of these results was similar to that for $\mathrm{dC}_{8}$ and $\mathrm{dT}_{8}$ as discussed above. It was thus concluded that the stabilities of single-stranded oligonucleotides exposed to ARTP were strongly influenced by the bases present.

Molecular dynamic simulation of the oligonucleotides. Considering that potential energy level can reflect the stability of a matter to a certain extent, we used the molecular dynamic simulation with Discovery Studio v2.5 in terms of energy minimization of the oligonucleotides to determine their stability. Taking that the concentration of oligonucleotides we used in ARTP treatment was $200 \mathrm{mM}$, which was equivalent to that one oligonucleotide was solvated in around 300 water molecules into consideration, we constructed a cubic box with about 390 water molecules for solvation of a nucleotide for the molecular simulation (Fig. S3, Fig. S4). As shown in Table 2, the average potential energy for the respective $\mathrm{dA}_{8}, \mathrm{dT}_{8}, \mathrm{dG}_{8}, \mathrm{dC}_{8}$ and $\mathrm{dA}_{2} \mathrm{dT}_{2} \mathrm{dG}_{2} \mathrm{dC}_{2}$ used in the 


\begin{tabular}{|l|l|l|l|l|l|}
\hline & $\mathbf{d A}_{\mathbf{8}}$ & $\mathbf{d T}$ & $\mathbf{d G}$ & $\mathbf{d} \mathbf{C}_{\mathbf{8}}$ & $\mathbf{d A}_{\mathbf{2}} \mathbf{d T}_{2} \mathbf{d G}_{\mathbf{2}} \mathbf{d C}_{\mathbf{2}}$ \\
\hline Potential energy (kcal/mol) & $-6,465$ & $-6,308$ & $-6,491$ & $-6,365$ & $-6,173$ \\
\hline $\begin{array}{l}\text { Total molecules in a cubic box (Number of water molecules and oligonu- } \\
\text { cleotides) }\end{array}$ & 396 & 381 & 399 & 389 & 381 \\
\hline Average potential energy (kcal/mol/molecule) & -16.326 & -16.556 & -16.268 & -16.362 & -16.202 \\
\hline
\end{tabular}

Table 2. Potential Energy after energy minimization during the simulation.

experiment were $-16.326,-16.556,-16.268,-16.362$ and $-16.202 \mathrm{kcal} /(\mathrm{mol} / \mathrm{molecule})$, respectively. The average potential energy of the oligonucleotides was $\mathrm{dT}_{8}<\mathrm{dC}_{8}<\mathrm{dA}_{8}<\mathrm{dG}_{8}<\mathrm{dA}_{2} \mathrm{dT}_{2} \mathrm{dG}_{2} \mathrm{dC}_{2}$, indicating that the turn of the oligonucleotide stability was $\mathrm{dT}_{8}>\mathrm{dC}_{8}>\mathrm{dA}_{8}>\mathrm{dG}_{8}>\mathrm{dA}_{2} \mathrm{dT}_{2} \mathrm{dG}_{2} \mathrm{dC}_{2}$. This is consistent with our experimental results described above.

\section{Discussion}

Mutation is a hereditable change in the structure of DNA of an organism altered by physical or chemical mutagens either directly or indirectly. However, the main difficulty for an organism mutation is how to know the mutagenic effectiveness and in vivo variation in genomic DNA genomes with particular mutagens ${ }^{32,33}$. For example, ultraviolet radiation (UV) is one of widely used physical mutagens capable of inducing mutagenic DNA lesions ${ }^{34,35}$. The possible mutagenic mechanisms caused by UV-induced DNA damage were pyrimidine dimers such as cyclobutene-pyrimidine dimers, 6-4 photoproducts, and their Dewar valence isomers as well as DNA strand breaks by interfering the genome integrity ${ }^{34-36}$. By far, many mutagenesis approaches to damaging DNA to create mutations using physical mutagens (e.g., ${ }^{60} \mathrm{Co} \gamma$-rays, X-rays, UV light, radiofrequency radiation, etc.) ${ }^{37,38}$ have been studied and applied. Some of possible mutagenic mechanisms caused by physical mutagens have been elucidated ${ }^{34-40}$.

More and more experimental results have also showed that the ARTP as a new kind of physical mutation tool has a bright prospect for the genome mutation of the organisms with rapid mutation, high diversity of mutants and high safety ${ }^{1,4}$. Up to now, ARTP as a novel powerful mutagenesis method has been successfully used to mutation breeding of more than 110 kinds of microorganisms and plants as well animals ${ }^{19-22,25}$. Generally, mutagenesis of organisms is a complex process, dependent on the cellular DNA damage strength and the subsequent repair system of damaged DNA, which allows mutation to occur. Our previous study demonstrated that compared with UV and chemical mutagens, ARTP showed highest DNA damage strength per living cells and mutation rate per generation ${ }^{26}$. Thus, how to obtain the direct molecular evidence for the DNA base pair damage by ARTP irradiation is needed to understand the ARTP mutagenesis mechanisms.

In this study, the NMR spectroscopy and MALDI-TOF/MS employed to detect artificial chemical building blocks of DNA (mononucleotides and oligonucleotides) in vitro treated by ARTP, we successfully analyzed and deduced the mononucleotide and oligonucleotide products, respectively. Since this study aimed to explore the direct damage process of ARTP to oligonucleotides and no publication could be found as reference to design the experiment, we employed ARTP to treat the hetero-nucleotides with 2 residues which could be synthesized simply to predict what would happen in the structure of the simplified oligonucleotides. We found that altered ${ }^{31} \mathrm{P}$ triphosphate signals, and ${ }^{1} \mathrm{H}$ deoxyribose and base signals in the corresponding spectra of the mononucleotides indicated that treatment with plasma affected the structures of the mononucleotides. The ${ }^{31} \mathrm{P}-\mathrm{NMR}$ spectra directly indicated that the phosphate bonds of the mononucleotides were broken upon treatment with plasma. With different damaged-DNA results in vivo, which in clustered DNA damage of severity greater than simple double-strand breaks caused by ionizing radiation ${ }^{37}$, ARTP treatment broke the artificial oligo-nucleotides in vitro into small fragments, as evidenced by MALDI-TOF/MS. The purines of $\mathrm{dA}_{8}$ and $\mathrm{dG}_{8}$, and the purines minus their amino groups, were cleaved by treatment with plasma, and CMP, cytosine, and phosphate were released from $\mathrm{dC}_{8}$. Compared with the products found for $\mathrm{dA}_{8}, \mathrm{dG}_{8}$, and $\mathrm{dC}_{8}$, the structural stability of thymidine was greater than that of the other bases because we found that $\mathrm{dT}_{8}$ was hardly cleaved under the same experimental conditions. The structural alterations (stability) of the oligonucleotides in vitro induced by ARTP appeared to be attributable primarily to the base.

To further understand the stability of the synthesized oligonucleotides, molecular dynamic simulation was performed to generate the three dimensional pharmacophore model for simulation of the single-stranded homoand hetero-oligonucleotides used in this study (Figs. S3 and S4). Since the potential energy level obtained can reflect the stability of a matter, we used energy minimization to determine the stability of the oligonucleotides used in this study. The order of the stability was $\mathrm{dT}_{8}>\mathrm{dC}_{8}>\mathrm{dA}_{8}>\mathrm{dG}_{8}>\mathrm{dA}_{2} \mathrm{dT}_{2} \mathrm{dG}_{2} \mathrm{dC}_{2}$ (Table 2), which was consistent with our experimental results by ARTP treatment of the respective oligonucleotides.

The above experimental results showed that ARTP could diversely damage DNA base molecules, implying the effective mutation capability for many kinds of organisms as mentioned in Introduction. However, by far we still hardly link the current deduced results to organism mutation mechanism by ARTP in vivo, since for in vivo mutation, in addition to the direct breakage of DNA at the first step, the complicated repair system for the damaged DNA during cell survival growth is another important factor, which make the mutation process analysis complicated. Recently, whole-genome sequencing also revealed the in vivo mutation features of Japanese flounder, a sea fish of Paralichthys olivaceus caused by ARTP mutagenesis, which showed multiple SNP and InDel mutation sites and the average mutation rate was up to $0.064 \%$ at the genome level, which was $2-3$ order higher than the traditional mutagenesis methods ${ }^{23}$. According to bioinformatics analysis, the higher mutation rates were 
found in many key genes associated with cellular process, metabolic process, biological regulation processes, cell components, binding function and catalytic activity in mutated species of $P$. olivaceus ${ }^{23}$. By multiplex ARTP mutagenesis of Zymomonas mobilis, a bacterial strain for ethanol production, a mutant with improved tolerance to both high acetic acid concentration up to $8 \mathrm{~g} / \mathrm{L}$ and low $\mathrm{pH}$ down to $\mathrm{pH} 3.5$ was obtained, which showed enhanced growth and ethanol production under both sterilized/unsterilized conditions at $\mathrm{pH} 4.0$ or $3.5^{24}$. By genomic resequencing analysis of the tolerant mutant, eleven single nucleic variations (SNVs) found to be likely related to acetic acid and low $\mathrm{pH}$ tolerance, and these SNVs were interestingly distributed between genes of ZMO0952 and ZMO0956, ZMO0152 and ZMO0153, and ZMO0373 and ZMO0374 in the genome, indicating the uniqueness of ARTP mutagenesis for strain improvement ${ }^{24}$. Taken together with these examples of ARTP mutagenesis, the present study showed the first-hand evidence for the DNA base damage pattern by ARTP irradiation. More studies on the comparative bioinformatic analysis for the selected different mutants from one same starting organism by ARTP mutagenesis will be needed further to provide deep insights into comprehensive molecular mutation mechanism of the mutated organisms by genotype and phenotype association.

\section{Conclusions}

In this study, we found that various chemical structural changes to the artificial mononucleotides and oligonucleotides that may account mutagenesis for the wide and successful applications reported for ARTP-induced mutation breeding of diverse microbes and plants as well animals caused by ARTP treatment. The results of ${ }^{31} \mathrm{P}$-and ${ }^{1} \mathrm{H}$-NMR for the plasma-treated and untreated mononucleotides indicated that the chemical natures of the mononucleotides determined their stability to irradiation with ARTP and dATP was less stable than were the other mononucleotides. The oligonucleotides after treatment with ARTP have been cleaved bonds and broken into small fragments as detected by mass spectrometry. The stabilities of the oligonucleotides differed to ARTP irradiation, with $\mathrm{dT}_{8}$ being the most stable and was more beneficial to stabilizing single-stranded oligonucleotide structures compared to the other base groups (A, G, and C). The different structure stability of the oligonucleotides to ARTP irradiation was also confirmed by the molecular dynamic simulation. The order of average potential energy of the oligonucleotides was $\mathrm{dT}_{8}>\mathrm{dC}_{8}>\mathrm{dA}_{8}>\mathrm{dG}_{8}>\mathrm{dA}_{2} \mathrm{dT}_{2} \mathrm{dG}_{2} \mathrm{dC}_{2}$. Therefore, these changes of chemical building blocks of DNA also provide a basic insight into the mechanism understanding of ARTP mutagenesis, a tool that has been widely applied for mutation breeding of different organisms. And also the ARTP as a powerful mutagenesis method will feasibly contribute to the progress of a comprehensive study on an organism mutation and evolution.

\section{Materials and methods}

Sample preparations. The mononucleotides dATP, dGTP, dCTP, and dTTP were purchased from Takara Co., Ltd (Dalian, China). The single-stranded oligonucleotides $\mathrm{dA}_{8}, \mathrm{dT}_{8}, \mathrm{dG}_{8}, \mathrm{dC}_{8}$, and $\mathrm{dA}_{2} \mathrm{dT}_{2} \mathrm{dG}_{2} \mathrm{dC}_{2}$ were synthesized and purified with HPLC by Invitrogen Life Technologies Ltd (Shanghai, China). The mononucleotides and oligonucleotides were dissolved in distilled, nuclease-free water at concentrations of 100 and $200 \mathrm{mM}$, respectively, and for each sample, $5 \mu \mathrm{L}$ was subjected to ARTP treatment.

ARTP jet instrumentation. The equipment used to generate the helium radio-frequency ARTP jet consists of a 13.56-MHz power supply, a co-axial-type plasma generator, a helium gas supply and control subsystem, and a stainless-steel sample plate that can be moved smoothly in the vertical direction to adjust the stand-off distance between the plasma torch nozzle exit and the sample plate ${ }^{26,27}$ (Fig. 1). The experimental parameters were as follows: The radio-frequency power input was $120 \mathrm{~W}$, the stand-off distance was $2.0 \mathrm{~mm}$, and the plasma jet temperature $2.0 \mathrm{~mm}$ downstream of the plasma torch nozzle exit was $<40{ }^{\circ} \mathrm{C}$ (Fig. 1 ).

NMR spectroscopy. After repeated lyophilization with $\mathrm{D}_{2} \mathrm{O}$ solution, the freeze-dried samples were dissolved in $0.5 \mathrm{~mL}$ of $99 \% \mathrm{D}_{2} \mathrm{O}$ (Sigma) for NMR studies. ${ }^{31} \mathrm{P}$ - and ${ }^{1} \mathrm{H}-\mathrm{NMR}$ spectroscopy were performed according to the reference with slight modification ${ }^{41,42}$. Briefly, for ${ }^{31} \mathrm{P}$ - NMR spectroscopy, the solution-state 31P NMR spectra were acquired at $24^{\circ} \mathrm{C}$ using a JEOL ECA 600 spectrometer (JEOL Ltd., Japan) operating at $243 \mathrm{MHz}$ with a $45^{\circ}$ pulse width $(5.2 \mu$ s pulse), an acquisition time of $0.77 \mathrm{~s}$ ( $50 \mathrm{ppm}$ window centered at $0 \mathrm{ppm})$, a delay time of $2.0 \mathrm{~s}$. The chemical shifts were determined in relation to external $85 \% \mathrm{H}_{3} \mathrm{PO}_{4}($ at $\delta=0)$. All of the spectral results were processed with the NMR Utility Transform Software (NUTS) for Windows (Acorn NMR, Livermore, CA). Signals for P compounds or functional groups were determined according to literature ${ }^{43}$.

For ${ }^{1} \mathrm{H}-\mathrm{NMR}$ spectroscopy, the ${ }^{1} \mathrm{H}$ spectra were recorded on a JOEL JNM ECA-600 spectrometer operating at $600.17 \mathrm{MHz}$ at $25^{\circ} \mathrm{C}$ with $\mathrm{D}_{2} \mathrm{O}$ as the internal lock. All ${ }^{1} \mathrm{H}$ NMR spectra were acquired with inverse detection probe. The parameters used were 32 sans, 16,384 points, spectral width of $15 \mathrm{ppm}, 90^{\circ} \mathrm{C}$ pulse length of $5.2 \mu \mathrm{s}$ and relaxation delay of $2 \mathrm{~s}$. To suppress the residual water signals, a pre-saturation sequence was used at the water frequency during the recycle delay. ${ }^{1} \mathrm{H}$ NMR spectra free induction decays were zero filled to $64 \mathrm{~K}$ before Fourier transformation, and then were transformed with a line broadening factor of 0.3 . Transformed ${ }^{1} \mathrm{H}$ spectra were manually phased, baseline corrected and calibrated to TMSP at $0.0 \mathrm{ppm}$ with Mnova (version 8.1.2, Bruker). 2D NMR spectra including ${ }^{1} \mathrm{H} \mathrm{J}$-resolved spectroscopy (JRES), ${ }^{1} \mathrm{H}-{ }^{1} \mathrm{H}$ correlation spectroscopy $\left({ }^{1} \mathrm{H}-{ }^{1} \mathrm{HCOSY}\right),{ }^{1} \mathrm{H}-{ }^{1} \mathrm{H}$ total correlation spectroscopy $\left({ }^{1} \mathrm{H}-{ }^{1} \mathrm{H}\right.$ TOCSY $)$, heteronuclear single quantum coherence spectroscopy (HSQC) and heteronuclear multiple bond correlation (HMBC) were also recorded on the $600 \mathrm{MHz}$ JEOL spectrometer with parameters.

MALDI-TOF/MS. MALDI-TOF mass spectra were acquired on a Waters MALDI micro MX instrument to detect the product-ion $\mathrm{m} / \mathrm{z}$ values obtained for the plasma-treated and untreated oligonucleotides. The matrix was composed of $0.1 \%(\mathrm{w} / \mathrm{v}) 2$, 5-dihydroxybenzoic acid in a 50:50 (v/v) mixture of trifluoroacetic acid and 
acetonitrile. The matrix and each sample solution, $0.5 \mu \mathrm{L}$ each, were mixed, and $0.8 \mu \mathrm{L}$ of each mixture was individually and rapidly dropped into the sample well of the mass spectrometer and then dried at room temperature. The mass spectra were obtained in the negative mode on a time-of-flight Microflex mass spectrometer (Bruker), and the N2-laser excitation wavelength was $337 \mathrm{~nm}$. Spectra were calibrated using reference oligonucleotides of known masses.

Methods of energy minimization. Discovery Studio v2.5 (DS, www.accelrys.com) was used to generate the three dimensional pharmacophore model for the single-stranded homo- and hetero-oligonucleotides. All minimizations were based on CHARMM-27 force field. The oligonucleotides water models were used in order to create the aqueous environment. In DS, oligonucleotides were solvated in a cubic box with about 390 water molecules. Particles Mesh Ewald (PME) electrostatic and periodic boundary conditions were applied in all directions. The system was then subjected to a smart minimizer algorithm for minimization with 10,000 steps. Average Potential Energy of was defined as following equation: Average Potential Energy (kcal/mol $/ \mathrm{mol}$ ecule) $=$ Potential Energy $/ \mathrm{mol} / \mathrm{molecule}$ (including number of water molecules and oligonucleotide residues in one cubic box).

\section{Data availability}

No datasets were generated or analysed during the current study.

Received: 24 May 2019; Accepted: 9 August 2020

Published online: 31 August 2020

\section{References}

1. Ottenheim, C., Nawrath, M. \& Wu, J. C. Microbial mutagenesis by atmospheric and room-temperature plasma (ARTP): the latest development. Bioresour. Bioprocess 5, 12-26 (2018).

2. Liao, X. et al. Inactivation mechanisms of non-thermal plasma on microbes: a review. Food Control 75, 83-91 (2017).

3. Bourke, P., Ziuzina, D., Han, L., Cullen, P. J. \& Gilmore, B. F. Microbiological interactions with cold plasma. J. Appl. Microbiol. 123, 308-324 (2017).

4. Zhang, X. et al. Atmospheric and room temperature plasma (ARTP) as a new powerful mutagenesis tool. Appl. Microbiol. Biot. 98, 5387-5396 (2014).

5. d'Agostino, R., Favia, P., Oehr, C. \& Wertheimer, M. R. Low-temperature plasma processing of materials: past, Present, and Future. Plasma Process. Polym. 2, 7 (2005).

6. Nishimea, T. M. C. et al. Non-thermal atmospheric pressure plasma jet applied toinactivation of different microorganisms. Surf Coat Technol. 312, 19-24 (2017).

7. Li, H. et al. Radio-Frequency, Atmospheric-pressure glow discharges: producing methods, characteristics and applications in bio-medical fields. Complex Syst. 982, 584 (2008).

8. Lu, X. et al. Reactive species in non-equilibrium atmospheric-pressure plasmas: generation, transport, and biological effects. Phys. Rep. 630, 1-84 (2016).

9. Yasuda, H., Hashimoto, M., Rahman, M. M. \& Takashima, K. A Mizuno (2008) States of biological components in bacteria and bacteriophages during inactivation by atmospheric dielectric barrier discharges. Plasma Process. Polym. 5, 615 (2008).

10. Edelblute, C. M., Heller, L. C., Malik, M. A., Bulysheva, A. \& Heller, R. Plasma-activated air mediates plasmid DNA delivery in vivo. Mol. Ther. 3, e16028 (2016).

11. Szili, E. J. et al. The assessment of cold atmospheric plasma treatment of DNA in synthetic models of tissue fluid, tissue and cells. J. Phys. D Appl. Phys. https://doi.org/10.1088/1361-6463/aa7501 (2017).

12. Lerouge, S., Tabrizian, M., Wertheimer, M. R., Marchand, R. \& Yahia, L. Safety of plasma-based sterilization: surface modifications of polymeric medical devices induced by Sterrad(R) and Plazlyte (TM) processes. Biomed. Mater. Eng. 12, 3-13 (2002).

13. Sato, T. Sterilization mechanism for Escherichia coli by plasma flow at atmospheric pressure. Appl. Phys. Lett. 89, 399 (2006).

14. Raguse, M. et al. Understanding of the importance of the spore coat structure and pigmentation in the Bacillus subtilis spore resistance to low-pressure plasma sterilization. J. Phys. D Appl. Phys. 49, e285401 (2016).

15. Sardella, E., Palumbo, F., Camporeale, G. \& Favia, P. Non-equilibrium plasma processing for the preparation of antibacterial surfaces. Materials. 9, 515 (2016).

16. Gao, A., Hang, R. \& Chu, P. K. Recent advances in anti-infection surfaces fabricated on biomedical implants by plasma-based technology. Surf Coat Technol. 312, 2-6 (2017).

17. Gregory, F.. Materials for disinfection produced by non-thermal plasma.US Patent: US2017 0202218 A1.

18. Hideharu, S. Inactivation of bacterial spore, endotoxin, lipid A, normal prion and abnormal prion by exposures to several sorts of gases plasma. Biocontrol Sci. 21, 1-12 (2016).

19. Liu, X. et al. Erythritol production by Yarrowia lipolytica mutant strain M53 generated through atmospheric and room temperature plasma mutagenesis. Food Sci. Biotechnol. 64, 979-986 (2017).

20. Cao, S. et al. Improving of lipid productivity of the oleaginous microalgae Chlorella pyrenoidosa via Atmospheric and Room Temperature Plasma (ARTP). Bioresour. Technol. 244, 1400-1406 (2017).

21. Fan, X. et al. Improvement of uridine production of Bacillus subtilis by atmospheric and room temperature plasma mutagenesis and high-throughput screening. PLoS ONE https://doi.org/10.1371/journal.pone.0176545 (2017).

22. Ma, Y. et al. Significantly improving the yield of recombinant proteins in Bacillus subtilis by a novel powerful mutagenesis tool (ARTP): alkaline a-amylaseas a case study. Protein ExpresPur. 114, 82-88 (2015).

23. Hou, J. et al. Novel breeding approach for Japanese flounder using atmosphere and room temperature plasma mutagenesis tool. BMC Genom. 20, 323. https://doi.org/10.1186/s12864-019-5681-6 (2019).

24. Wu, B. et al. Engineered Zymomonas mobilis tolerant to acetic acid and low $\mathrm{pH}$ via multiplex atmospheric and room temperature plasma mutagenesis. Biotechnol Biofuels. 12, 10 (2019).

25. Lovett, S. T. Template-switching during replication fork repair in bacteria. DNA Repair 56, 118-128 (2017)

26. Zhang, X. et al. Quantitative evaluation of DNA damage and mutation rate by atmospheric and room-temperature plasma (ARTP) and conventional mutagenesis. Appl. Microbiol. Biotechnol. 99, 5639-5646 (2015).

27. Li, G. et al. Genetic effects of radio-frequency, atmospheric-pressure glow discharges with helium. Appl Phys Lett. 92, 1460-1543 (2008).

28. Li, H., Sun, W., Wang, H., Li, G. \& Bao, C. Electrical features of radio-frequency, atmospheric-pressure, bare-metallic-electrode glow discharges. Plasma Chem. Plasma Proc. 27, 529-545 (2007). 
29. Mann, M., Meng, C. K., Fenn, J. B. \& Chem, A. Interpreting mass spectra of multiply charged ions. Anal Chem. 61, 1702-1708 (2002).

30. Saenger, W. Structure and function of nucleosides and nucleotide. Angew. Chem. 12, 591-682 (1973).

31. Joy, L. H., Ottar, S. \& John, A. T. DNA base damage recognition and removal: new twists and grooves. Mutat. Res.-Fund. Mol. M. 577, 55-76 (2005).

32. Miral, D., Erdem, C. \& Pawel, J. Repair of oxidatively induced DNA damage by DNA glycosylases: mechanisms of action, substrate specificities and excision kinetics. Mutat. Res.-Rev. Mutat. 771, 99-127 (2017).

33. Strauss, B. S. Physical-chemical methods for the detection of the effect of mutagens on DNA. In Chemical Mutagens. 145-174 (1971).

34. Richa, R. P. \& Häder, D. P. Physiological Aspects of UV-Excitation of DNA. In Photoinduced Phenomena in Nucleic Acids II. 203-248 (2014).

35. Rastog, R. P., Kumar, R. A., Tyagi, M. B. \& Sinha, R. P. Molecular mechanisms of ultraviolet radiation-induced DNA damage and repair. J Nucleic Acids. 2010, 592980 (2010).

36. Sanear, A. Mechanisms of DNA excision repair. Science 266, 1954-1956 (1994).

37. Verschaeve, L. Genetic effects of radiofrequency radiation (RFR). Toxicol. Appl. Pharm. 207, 336-341 (2005).

38. Akamatsu, K., Shikazono, N. \& Saito, T. New method for estimating clustering of DNA lesions induced by physical/chemical mutagens using fluorescence anisotropy. Anal. Biochem. 536, 78-89 (2017).

39. Goodhead, D. T. Initial events in the cellular effects of Ionizing radiations: clustered damage in DNA. Int. J. Radiat Biol. 65, 7-17 (1994).

40. Kusakabe, M. et al. Mechanism and regulation of DNA damage recognition in nucleotide excision repair. Genes Environ. 41, 2 (2019).

41. Zhang, G. N., Chen, Z. H., Zhang, A. M., Chen, L. J. \& Wu, Z.J. Influence of climate warming and nitrogen deposition on soil phosphorus composition and phosphorus availability in a temperate grassland, China. J. Arid Land 6(2), 156-163 (2014).

42. Sun, J. R. et al. Similar metabolic changes induced by HIPVs exposure as herbivore in Ammopiptanthus mongolicus. PLoS ONE 9(4), e95474 (2014).

43. Zhang, A. M., Chen, Z. H. \& Zhang, G. N. Soil phosphorus composition determined by ${ }^{31}$ P NMR spectroscopy and relative phosphatase activities influenced by land use. Eur J. Soil Biol. 52(7), 73-77 (2012).

\section{Acknowledgements}

The authors thank Prof. Hai-Jun Yang of Tsinghua University and Prof. Xue-Juan Zou of Peking University for their kind help in analytical experiments. This work was supported by National Key Research and Development Plan, China (Grant No. 2016YFD0102106) and National Key Scientific Instrument and Equipment Project of NSFC (Grant No. 21627812).

\section{Author contributions}

X.H.X. and H.P.L conceived and supervised the research. L.Y.W. and H.X.Z. directed the research. L.Y.W., H.X.Z., X.H.X. and H.P.L. designed the experiments. L.Y.W., H.X.Z., Y.N.W., L.H.J., G.L. and N.S. conducted the experiments. L.Y.W., H.X.Z., X.H.X. and H.P.L. analysed the results. D. H. performed the molecular dynamic simulation. L.Y.W., H.X.Z. and X. H. X wrote the manuscript. All authors commented on the manuscript.

\section{Competing interests}

The authors declare no competing interests.

\section{Additional information \\ Supplementary information is available for this paper at https://doi.org/10.1038/s41598-020-71152-1.}

Correspondence and requests for materials should be addressed to H.L. or X.-H.X.

Reprints and permissions information is available at www.nature.com/reprints.

Publisher's note Springer Nature remains neutral with regard to jurisdictional claims in published maps and institutional affiliations.

(c) (i) Open Access This article is licensed under a Creative Commons Attribution 4.0 International License, which permits use, sharing, adaptation, distribution and reproduction in any medium or format, as long as you give appropriate credit to the original author(s) and the source, provide a link to the Creative Commons licence, and indicate if changes were made. The images or other third party material in this article are included in the article's Creative Commons licence, unless indicated otherwise in a credit line to the material. If material is not included in the article's Creative Commons licence and your intended use is not permitted by statutory regulation or exceeds the permitted use, you will need to obtain permission directly from the copyright holder. To view a copy of this licence, visit http://creativecommons.org/licenses/by/4.0/.

(c) The Author(s) 2020 